\title{
Preliminary Investigation of Outbreaks of Duck Virus Enteritis in Khaki Campbell Ducks in West Bengal
}

\author{
C. Jana ${ }^{1 *}$, S. K. Mukhopadhayay ${ }^{1}$, S. N. Joardar ${ }^{1}$ and B. Mondal $^{2}$ \\ ${ }^{1}$ Department of Veterinary Pathology, West Bengal University of Animal and Fishery \\ Sciences, K. B. Sarani, Kolkata, West Bengal, India \\ ${ }^{2}$ ERS, ICAR- Indian Veterinary Research Institute, Kolkata, India \\ *Corresponding author
}

\section{A B S T R A C T}

The study investigated two outbreaks in khaki Campbell ducks to understand the predisposing factors and nature of virus involved in such outbreaks. Two outbreaks suspected of duck virus enteritis (DVE) were attended at BudBud and Krishnanagar villages of West Bengal. Gross lesions were recorded and samples were collected for histopathology, molecular detection and virus isolation. The outbreaks were diagnosed as DVE by characteristic pathological lesions, diagnostic PCR assay and virus isolation. The

\section{Keywords}

Duck virus enteritis, Khaki Campbell duck, Pathology, Virulence

\section{Article Info}

Accepted:

20 December 2020

Available Online:

10 January 2021 virus was primarily isolated in embryonated duck eggs and identified as duck enteritis virus (DEV). The virulence of both isolates was investigated in 28-day-old khaki Campbell ducklings $(\mathrm{n}=12)$. Three groups ( $\mathrm{Gr}$ I, Gr II and Gr III) were designed with 4 ducklings in each group. Ducklings of Gr I and Gr II were infected intra peritoneally with $0.2 \mathrm{ml}$ of chorioallantoic membrane (CAM) suspensions of DEV/BudBud/11 and DEV/ Nadia /12 virus isolates, respectively. In ducklings of Gr III, $0.2 \mathrm{ml}$ of PBS was injected in same route. The clinical and pathological findings in both infected groups were characteristics of the DVE. Clinical signs were marked by loss of voice, anorexia, hyperthermia, dullness, unwilling to move, diarrhea, lameness, increased thirst and death. But there was difference in clinical course and features of diarrhea between two infected groups. Pathological findings were petechiation in heart, liver, spleen, kidney, proventriculus and intestine, atrophy of bursa with exudates in the lumen of both infected groups. There were inclusion bodies in hepatic cells and lymphoid cells. But most distinguished microscopic lesions were noticed in liver, proventriculus and bursa of Fabricius in both two groups. In conclusion, the investigation suggests to follow improved health care practices in backyard duck farming based on analysis of predisposing factors. Further the experimental study revealed that virus isolates associated in outbreaks are different in virulence and isolates may be explored in production of immune-diagnostics and attenuated live vaccine.

\section{Introduction}

Duck virus enteritis (DVE) is a contagious disease of waterfowl such as ducks, geese and swans. The etiology of disease is duck enteritis virus (DEV), which is grouped into the Mardivirus genus of subfamily Alphaherpesvirinae, belongs to the family 
Herpesviridae (King et al., 2011). The virus has linear double-stranded DNA genome of about $158 \mathrm{kbp}$. It causes a considerable economic loss to the backyard as well as commercial duck farms due to decreased production, condemnation of meat and mortality. It also poses a potential threat to the duck population especially for its latency and reactivation phenomena. The clinical signs and pathological lesions vary with species, age, sex, immune status and nature of virus. Besides sudden death, the clinical signs of the disease include dullness, ruffled feather, loss of appetite, polydipsia, lacrimation, photophobia, ataxia, greenish watery diarrhoea and dehydration (Kulkarni et al., 1995). The main lesions are characterized by vascular damage, diffuse haemorrhages and fibrinous inflammation in the digestive tract, lymphoid necrosis in the thymus and bursa of Fabricius (Shawky et al., 2000; Salguero, et al., 2002).

As with many viruses, DEV has various strains worldwide which differ in virulence in domestic ducks and wild water fowls. Based on mortality, morbidity and pathogenesis in ducklings and adult ducks, DEV could be classified as avirulent, low virulent, virulent and highly virulent (or hyper-virulent) strains. Some avirulent DEV strains have been shown to produce no mortality in commercial Pekin ducks (Anas platyrhynchos) flock although egg production declined $95 \%$.

On the other hand, hyper-virulent (or highly virulent) virus strain has also been reported to cause high mortality (75\%) and hemorrhagic and necrotic gross lesions in four months old mule ducks (Marius-Jestin et al., 1987). Some researchers described that the virulent strains were those that killed adult mallards and low virulent strains were those that killed hatchling mallards but not the adult mallards (Spieker et al., 1996).
In India, DVE was first reported in the early 1960s (Mukherji et al., 1963) and since then the disease has spread in many duck rearing states namely, West Bengal (Bhowmik and Chakorborty, 1985), Assam (Konch et al., 2009), Andhra Pradesh (Umamaheswara rao and Rao, 1993), Tamil Nadu (Pazhanivel et al., 2019) and Kerala (Soman et al., 2014). In West Bengal, outbreaks in domestic ducks have been reported several times in last five decades (Mukherji et al., 1963; Bhowmik and Chakorborty, 1985 and Mandal et al., 2017) and it is likely that DEV strains of varying virulence are circulating in the field. In this context, the present report describes about outbreaks of duck virus enteritis in West Bengal, isolation of virus and nature of isolates.

\section{Materials and Methods}

Outbreaks: A suspected DVE outbreak in a flock of khaki Campbell ducks was attended at BudBud village, Burdwan district, West Bengal in autumn season. Detail history and clinical signs were recorded. The farmer maintained unvaccinated grower under backyard farming and allowed them to forage in a common pond where deshi ducks also accessed regularly. The grower ducks $(n=22)$ showed clinical signs of lethargy, inappetence, lacremation, lameness, whitish diarrhoea, dehydration followed by death. All grower ducks died and the duration of disease course was 10 days.

Another outbreak in adult ducks was investigated at Krishnanagar, Nadia district, West Bengal in summer season. Khaki Campbell ducks $(n=32)$ were procured 1 month ago by the farmer from local vendor. Ducks were unvaccinated and reared under backyard farming. From the beginning, birds were allowed to access common ponds where other indigenous ducks also foraged. There was history of sudden death and ailing birds 
had clinical signs of dullness, ruffled feather, anorexia, polydipsia, lameness, nasal discharge, profuse diarrhea and dehydration followed by death. The duration of illness was 7 days and all ducks died.

Sampling: Six dead ducks from each outbreak were subjected for post mortem examinations and gross lesions were recorded. Some parts of liver, spleen, thymus, esophagus, proventriculus, intestine, heart and bursa of Fabricius were collected from both outbreaks and preserved in $10 \%$ neutral buffered formalin for histopathology. A portion of liver showing lesions was collected from all necropsied ducks of each outbreak. The tissue preserved in $-80{ }^{\circ} \mathrm{C}$ and used for molecular detection and virus isolation.

Histopathology: The formalin- fixed tissues were processed by paraffin embedded technique and sections were cut at $5 \mu \mathrm{m}$ thickness. Cut sections were stained with hematoxylin and eosin (HE) (Bancroft and Stevens, 1996). Duplicate sections were stained with Giemsa for demonstration of inclusion body.

Molecular detection by PCR assay: DNA was isolated from infected livers (about 100 $\mathrm{mg}$ ) using the DNeasy Blood and Tissue Kit (Qiagen). PCR assay was performed using published primers (UL-F: 5'- GGCTG GTATGCGTGACAT-3' and UL-R 5'GTATTGGTTTCTGAGTTGGC-3') as described earlier (Mondal et al., 2010). Amplicons were analyzed by agarose gel electrophoresis.

Isolation of virus and identification: One PCR positive liver sample from each outbreak was taken and $10 \%$ tissue suspension in phosphate buffered saline (PBS) (pH-7.2) was prepared aseptically. It was centrifuged at $8000 \mathrm{rpm}$. The supernatant was filtrated through $0.45 \mu \mathrm{m}$ filter. The filtrated suspension of $100 \mu \mathrm{l}$ was inoculated onto chorioallantoic membrane (CAM) of 9 days old embryonated duck eggs $(n=5)$ and incubated at $37^{\circ} \mathrm{C}$. Sterile PBS $(100 \mu \mathrm{l})$ was inoculated in 9 days old embryonated duck eggs $(n=5)$ in same procedure for control. All inoculated eggs were monitored to observe embryopathy. After harvesting of virus, a portion of infected CAM was fixed in $10 \%$ neutral buffered formalin and processed for histopathological studies. Virus identification was carried out in infected CAM suspension by PCR assay (Mondal et al., 2010). The duck embryo lethal dose 50 (DELD 50) of each isolate was determined as per Reed and Muench (1938) formula using 9 days old embryonated duck eggs in 10 fold dilution.

Assessment of virulence of both isolates in khaki Campbell ducklings: The virulence of present isolates (named as DEV/ BudBud/11 and DEV/Nadia/12) was assessed in 28-day-old khaki Campbell ducklings. Twelve normal ducklings of both sexes were procured from state livestock farm, Kalyani, West Bengal. The stool samples of all duckling were screened for DEV by PCR (Mondal et al., 2010) and all found to be negative. Three groups (Gr I, Gr II and Gr III) were designed with 4 ducklings in each group and housed separately with feed and adlibitum water. Ducklings of Gr I and Gr II were infected intra peritoneally with $0.2 \mathrm{ml}$ of CAM suspensions of DEV/BudBud/11 and $\mathrm{DEV} /$ Nadia /12 virus isolates, respectively. The virus titres of CAM suspension of both isolates were adjusted as $10^{6.68} \mathrm{DELD}_{50 /} \mathrm{ml}$. Ducklings of control group (Gr III) injected with $0.2 \mathrm{ml}$ of PBS by same route. The details clinical observations were recorded. Gross lesions of different organs were recorded in details after post-mortem examination of dead and euthanized ducklings. Liver, spleen, thymus, bursa, esophagus, proventriculus, small intestine, heart and kidney having active lesions were fixed in $10 \%$ neutral buffered 
formalin for histopathological studies. Histopathology was performed as mentioned earlier. Liver and spleen were taken from dead birds for virus isolation in embryonated duck eggs and further confirmation by DEV specific PCR (Mondal et al., 2010).

\section{Results and Discussion}

\section{Gross pathological findings in outbreaks}

Common necropsy findings of both outbreaks (Bud Bud and Nadia) included petechiation in skin, liver (Fig. 1a), proventriculus (Fig. 1b), intestine, spleen, thymus and bursa of Fabricius. The liver was enlarged with numerous whitish spots of necrotic foci. In the heart, petechiae were found in and around the coronary groove. Focal grayish white patches were seen in the ventricular surface of myocardium. Haemorrhages were also revealed in endocardium on incision. In BudBud outbreak, patchy diphtheritic lesion in esophagus was noticed in all birds. However in Nadia outbreak, haemorrhagic spots were noticed in esophageal lumen without formation of diphtheritic lesion. Other important findings were noticed in Nadia outbreak as free clotted blood in body cavity and haemorrhages in ovaries of layer ducks.

\section{Microscopic findings}

\section{Bud Bud outbreak}

Liver and spleen: Congestion, haemorrhages within the sinusoids, cytoplasmic vacuolation and necrosis of hepatic cells (Fig. 2a) were observed in liver with infiltration of heterophils in around the central vein and portal areas. Intranuclear inclusion bodies were found in necrotic hepatocytes. The splenic parenchyma showed hyperaemia, haemorrhage and depletion of lymphocytes.
Esophagus: The muscularis layer was edematous and showed degenerative changes. There was degeneration and necrosis of stratified squamous epithelium of the esophagus. Desquamations of lining epithelium were observed with infiltration of heterophils at focal areas. Intranuclear inclusion bodies were observed in epithelial cells.

Proventriculus: Submucosal gland of proventriculus showed haemorrhages. Edema and degeneration of muscular layer were observed with cellular infiltration.

Small intestine: Hyperaemia and haemorrhages were observed in all layers of small intestines from the mucous membrane to the intestinal muscle. Degenerated and necrosed epithelial cells were detached from tip of villi (Fig. 2b) with accumulation into the lumen of small intestine admixed with blood cells.

Heart: Lesion in heart comprised of edema, degeneration and necrosis of myocardium with infiltration of heterophils and lymphocytes.

Bursa of Fabricius: Bursa of Fabricius had severe necrosis of lymphoid cells and depletion of lymphocytes. At places, the follicles were replaced by eosinophilic materials mixed with heterophils. Most of the bursal follicles were devoid of lymphocytes and cystic places were present.

Thymus: Lymphoid necrosis and depletion of lymphocytes in cortex and medulla were seen in thymus. Mild haemorrhages were found throughout the organ.

Nadia outbreak: Microscopic lesions in liver, spleen, esophagus, intestine and heart were almost similar to those found in BudBud outbreak but lesions in proventriculus and 
bursa of Fabricus were severe in Nadia outbreak.

Molecular detection of viral DNA in infected tissue: A diagnostic PCR assay clearly amplified a fragment of DNA polymerase gene. The assay was found to amplify a product of $\sim 610 \mathrm{bp}$, resolved in $1 \%$ agarose gel.

\section{Isolation and identification of virus}

The virus was primarily isolated from both outbreaks in embryonated duck eggs. In first passage, death of embryo was observed on 10 days post inoculation (p.i.) and 5 days p.i in BudBud and Nadia outbreak, respectively. CAM of dead eggs showed congestion and thickening of membrane without pock lesions. There was stunted growth of embryos and extensive haemorrhages on head, dorsal surface of tongue, liver and intestine. Histopathological studies of CAM revealed thickening of membrane with massive haemorrhages and pocket of inflammatory zone infiltrated with heterophils and lymphocytes. The isolates were confirmed as DEV by amplification (610 bp) of viral DNA polymerase gene using the diagnostic PCR.

\section{Assessment of virulence of both isolates in khaki Campbell ducklings}

\section{Clinical signs}

Clinical features of infected ducklings (Gr I and Gr II) were summarized in table1 and onset of clinical signs in both infected groups were observed within 84-96 hrs p.i.. Clinical signs were loss of voice, anorexia, hyperthermia, dullness, unwilling to move, frequent greenish to watery diarrhoea, lameness and increased thirst. All ducklings in both infected groups were found dead except one duckling in Gr I. Clinical sign in one bird in Gr I was subsided on $10^{\text {th }}$ day p.i.
No clinical abnormalities and death were observed in control group.

\section{Pathological findings in experiment ducklings}

\section{Gross lesions}

Gr I (DEV/BudBud/11): The gross pathological observations in most of the duckling were the petechial haemorrhages beneath the skin. Petechiae were more prominent in heart, liver, spleen, pancreas, kidney, proventriculus and intestine. Liver was congested and enlarged with necrotic foci throughout the outer surface of the organ. Diphtheritic lesions on the esophageal mucosal fold were most characteristic findings in this isolates (Fig.-3a). The inner surface of proventriculus had whitish mucous debris. The junction of proventriculus and gizzard showed erythematous mass. There was enlargement of spleen. Thymic and bursal atrophy were present and bursal lumen was filled with whitish exudates.

Gr II (DEV/Nadia/12): Massive haemorrhages under skin and free blood in body cavity were observed in ducklings. Petechial haemorrhages were noticed in spleen, endocardial surface of heart, kidneys, proventriculus, intestine and pancreas in all dead ducklings. Liver was highly enlarged and haemorrhagic with multiple grayish white necrotic spots. Dead ducklings manifested only necrotic patches and ecchymotic haemorrhages in the longitudinal fold of esophagus (Fig.- 3b). Mucosa of proventriculus had ulcerative areas. Severe congestion and mucosal haemorrhages were found in small and large intestines. A cheesy exudation mixed with blood was observed within the lumen of bursa. There were massive haemorrhages in thymus and enlargement of spleen. 
No gross lesions were observed in parenchymatous organs, lymphoid organs and digestive tract of control ducklings (Gr III) during the experiment period.

\section{Microscopic changes}

Most common histopathological lesions observed in two induced groups were hyperaemia, haemorrhages, cellular infiltration, necrosis and detachment of epithelial cells in parenchymatous organs, G.I. tract and lymphoid organs. Eosinophilic intranuclear inclusion bodies (INBs) were present in hepatocytes adjacent to necrosed area in all cases. In esophagus, extensive necrotic areas involving muscularis and submucosal layers with infiltration of heterophils and lymphocytes were noticed. In Intestine, the lining epithelial cells of the villi showed degenerative changes and necrosis and contained INBs. In heart, there were myocardial degeneration and extensive necrosis of muscle fibres infiltrated with heterophils and lymphoid cells in both infected groups. Edematous fluid caused separation of the muscle fibres in many places. Thymic lesions consisted of severe necrosis and depletion of lymphocyte and haemorrhages. Some of the lymphocytes contained eosinophilic INBs. Normal architecture of thymus was destroyed and epithelial cells also affected. Histopathological changes in kidney consisted of extensive haemorrhages, congestion and tubular degeneration. Splenic sinusoids were engorged and there was depletion of lymphoid cells. But in the present study, most distinguished microscopic lesions were noticed in liver, proventriculus and bursa of Fabricius

\section{Liver}

Gr I (DEV/BudBud/11): Haemorrhages in the liver parenchyma, mild cytoplasmic vacuolation, degeneration and necrosis of hepatocytes with infiltration of heterophils were observed. Many hepatocytes near to necrotic zone had INBs. Necrosis was observed in epithelium of bile duct.

Gr II (DEV/Nadia/12): Liver had engorgement of sinusoid, severe cytoplasmic vacuolation, massive haemorrhages, degeneration and severe coagulative necrosis with disruption of hepatic cords. There was massive infiltration of heterophils around the necrotic zones. INBs were seen in some degenerating hepatic cells with clear halos. Necrosis in epithelium of bile duct was similarly noticed as observed in Gr I.

\section{Proventriculus}

Gr I (DEV/BudBud/11): Mild haemorrhages were observed in the submucosal gland of proventriculus. The muscular layers were edematous and showed Zenker's degeneration with evidence of inflammatory reaction characterized by cellular infiltration. Lumens of submucosal gland were filled with exudates (Fig.4a).

Gr II (DEV/Nadia/12): Lesions consisted of severe congestion of blood vessels of inter submucosal glands, massive haemorrhages and necrotic mass infiltrated with heterophils and blood debris within the lumen of these glands (Fig. 4b). Muscular layers were highly edematous and also showed Zenker's degeneration.

\section{Bursa of Fabricius}

Gr I (DEV/BudBud/11): Epithelium of lymphoid fold of bursa was desquamated with accumulation in the lumina of the gland. Mild necrosis and depletion of lymphoid cells in the follicles were observed in this group (Fig. $4 \mathrm{c}$ and $4 \mathrm{~d}$ ). Atrophy of bursal follicles was observed with proliferation of fibrous tissues in interfollicular spaces. 
Gr II (DEV/Nadia/12): Lesions in bursa consisted of desquamation of epithelium of lymphoid fold, severe necrosis and depletion of lymphocyte within the follicles and haemorrhages. In many places, there was empty of follicles due to severe lymphiod destruction and distortion of follicles (Fig. 4e and 4f).

Gr III (control): No detectable microscopic changes in liver, pancreas, esophagus, proventriculus, intestine, heart, thymus, spleen and kidney were observed in control group.

Virus was re-isolated from liver and spleen of induced ducklings (dead and sacrificed) using 9 day-old embryonated duck eggs and confirmed by detecting $610 \mathrm{bp}$ fragment of DNA polymerase gene of the virus by PCR assay. No virus was isolated from control group in repeated attempts.

Table.1 Clinical observations in experimental ducklings

\begin{tabular}{|c|c|c|c|c|c|c|c|c|c|c|c|}
\hline \multirow[t]{2}{*}{ Group } & \multirow[t]{2}{*}{$\begin{array}{l}\text { On set of } \\
\text { pyrexia }\end{array}$} & \multirow[t]{2}{*}{$\begin{array}{l}\text { Mortality } \\
\text { start }\end{array}$} & \multirow[t]{2}{*}{ Morbidity } & \multirow[t]{2}{*}{ Mortality } & \multicolumn{5}{|c|}{ Diarrhoea } & \multicolumn{2}{|c|}{$\begin{array}{l}\text { Temperature } \\
\text { reaction }\end{array}$} \\
\hline & & & & & $\begin{array}{l}\text { On set of } \\
\text { diarrhea }\end{array}$ & Frequency & Colour & $\begin{array}{c}\text { Consiste } \\
\text { ncy }\end{array}$ & $\begin{array}{l}\text { Blood } \\
\text { in } \\
\text { stool }\end{array}$ & $\begin{array}{c}\text { At } 84 \\
\text { hr } \\
\left({ }^{\circ} \mathrm{C}\right)\end{array}$ & $\begin{array}{l}\text { At } 120 \\
\text { hr }\left({ }^{\circ} \mathrm{C}\right)\end{array}$ \\
\hline $\begin{array}{l}\text { Gr-I } \\
\text { (DEV/ } \\
\text { Bud } \\
\text { Bud/11 }\end{array}$ & 96 hr p.i. & 168 hr p.i. & $4 / 4$ & $3 / 4$ & $\begin{array}{l}120 \mathrm{hr} \\
\text { p.i. }\end{array}$ & $\begin{array}{l}\text { 3-4 times } \\
/ \mathrm{hr}\end{array}$ & Greenish & $\begin{array}{c}\text { Semi } \\
\text { solid } \\
\text { followed } \\
\text { by } \\
\text { watery }\end{array}$ & No & 43.0 & 44.2 \\
\hline $\begin{array}{l}\text { Gr-II } \\
\text { (DEV/ } \\
\text { Nadia/12 }\end{array}$ & 84 hr p.i. & 148 hr p.i & $4 / 4$ & $4 / 4$ & 96 hr p.i & $\begin{array}{c}6-7 \\
\text { times/hr }\end{array}$ & $\begin{array}{l}\text { Whitish } \\
\text { followed } \\
\text { by gray } \\
\text { yellow }\end{array}$ & Watery & Yes & 43.6 & 44.6 \\
\hline
\end{tabular}

Fig.1 Representative gross lesions of both outbreaks in duck; a. Multiple petechiae throughout the body, b. Haemorrhages in the proventriculus and heart

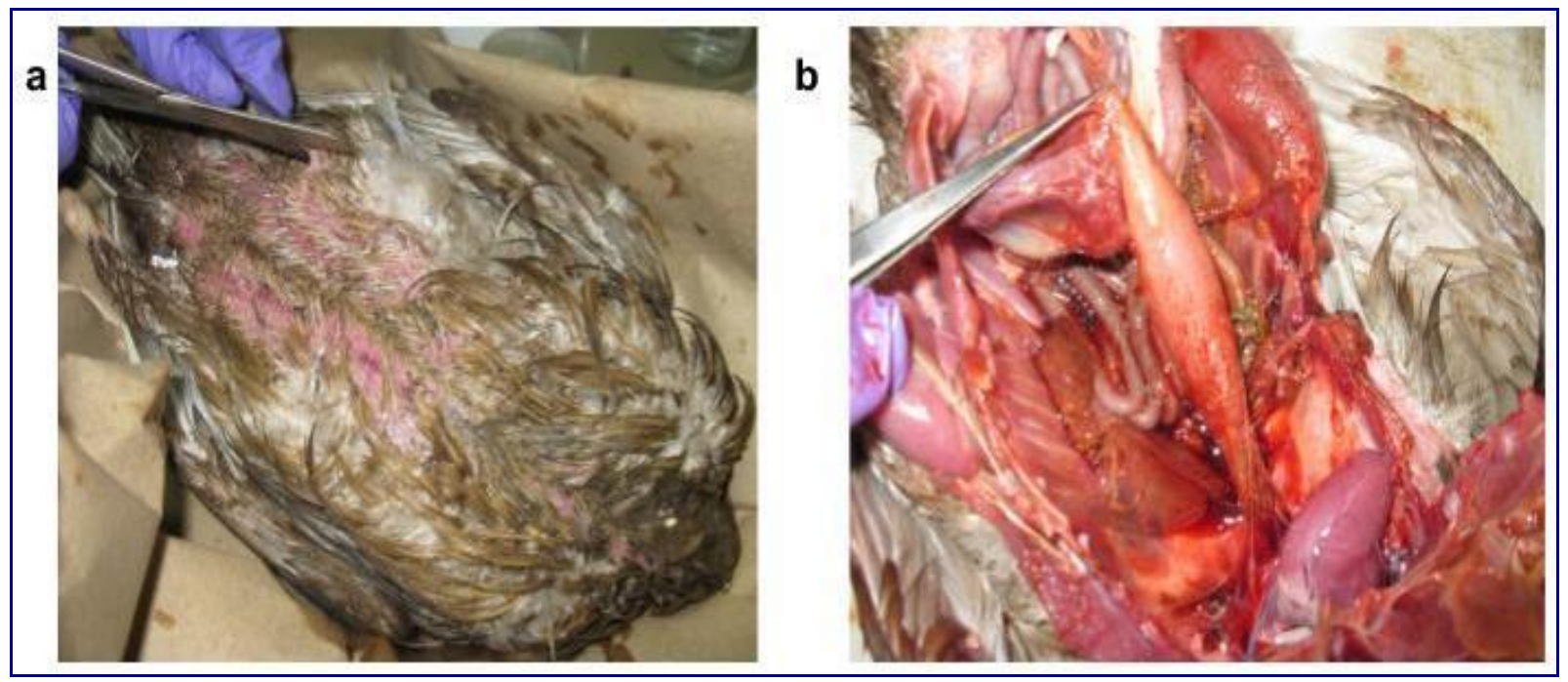


Fig.2 Representative microscopic findings in both outbreaks; a. Liver showing coagulative necrosis and cytoplasmic vacuolation $(\mathrm{HE}, 10 \mathrm{x})$, b. Epithelium of intestine showing necrosis with necrotic detritus (HE, 10x)

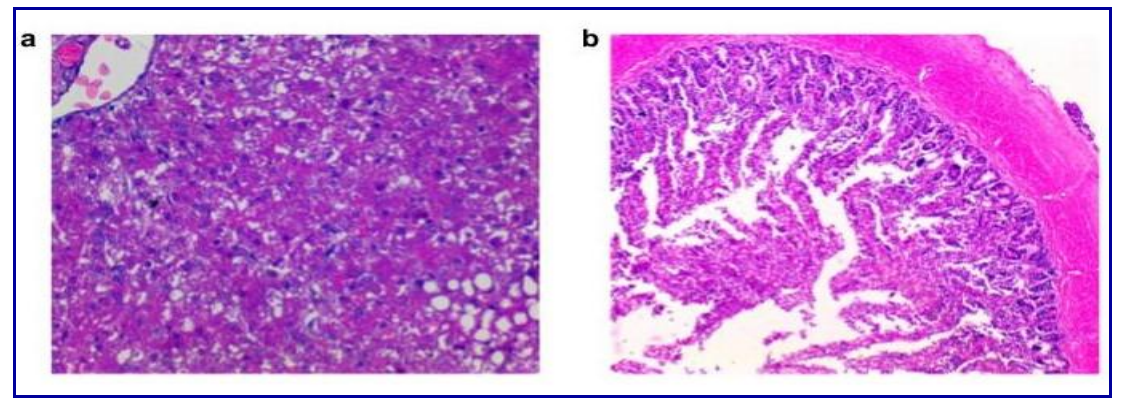

Fig.3 Distinguishable pathological lesions between two infected groups; a. Esophagus showing diptheretic lesions in Gr-I (DEV/BudBud/11), b. Esophagus showing haemorrhages and necrotic patches in Gr-II (DEV/Nadia/12)

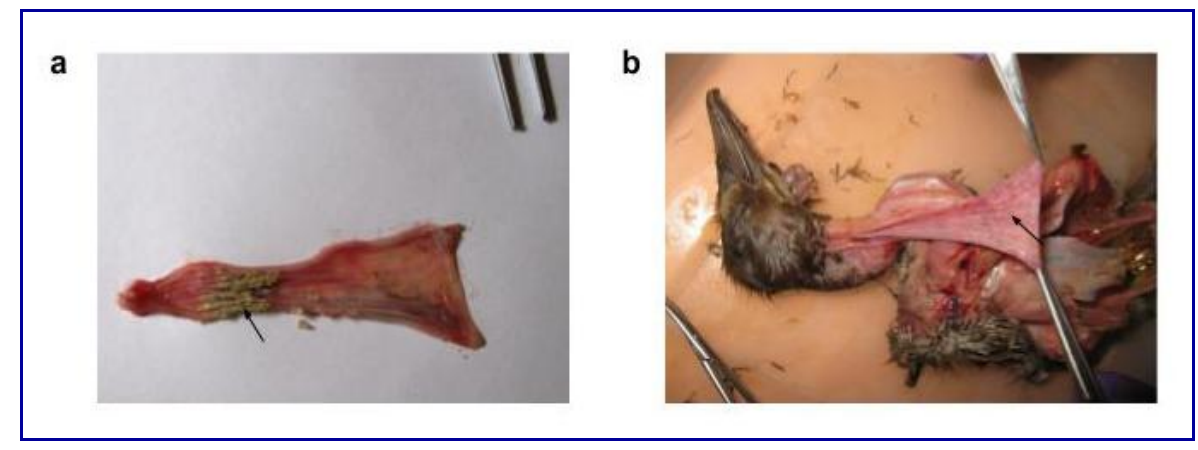

Fig.4 Distinguishable microscopic lesions between two infected groups; a. Necrosis of lining epithelium and haemorrhages in proventriculus of Gr-I (DEV/BudBud/11) (HE, 10x), b.

Necrosis of lining epithelium with massive haemorrhage and congestion in proventriculus of Gr II (DEV/Nadia/12) (HE, $10 \mathrm{x})$, c. Bursa showing atrophy \& proliferation of fibrous tissue in interfollicular spaces of Gr-I (DEV/BudBud/11)(HE, 10x), d. Bursa showing mild lymphoid cell depletion of Gr-I (DEV/BudBud/11)(HE, 40 x), e. Bursa showing haemorrhages and massive lymphoid cell depletion in Gr II (DEV/Nadia/12) (HE, $10 \mathrm{x}$ ) and f. Bursa showing severe necrosis with formation of cystic space within follicle of Gr II (DEV/Nadia/12)(HE, 40x)

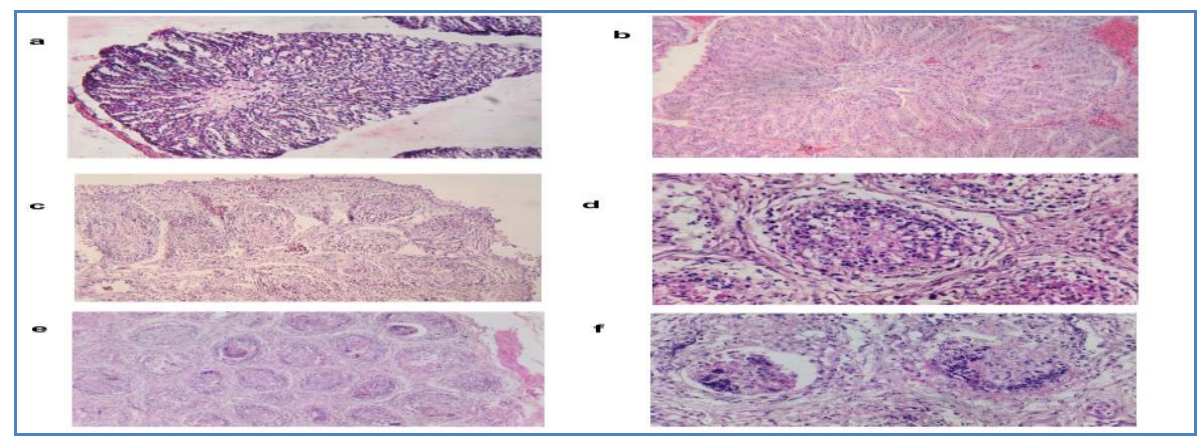


The duck virus enteritis is a contagious disease of ducks and is being reported several times from duck rearing states of India including West Bengal. As a control measure, vaccination against the disease is being practiced in this state but sporadic outbreak in fresh flock has also been noticed among ducks reared under backyard production system (Mandal et al., 2017). Therefore, the investigation on disease outbreak in khaki Campbell ducks reared under backyard management insights its predisposing factors, management risk and nature of circulating virus. The clinical signs and pathological lesions of spontaneous outbreaks helped to screen the disease primarily and it was confirmed by diagnostic PCR assay. In both outbreaks, it may be possible that free accessing to common ponds with indigenous ducks is the potential source of infection to the fresh flock.

The history revealed that the ignorance of quarantine practice and failure to follow up recommended vaccination schedule are critical management faults of the farmers. Disease outbreak at BudBud was occurred during season change in West Bengal.

Many outbreaks were recorded earlier during season change which might cause environmental stress to alter the immune status of birds (Burgess and Yuill, 1983). Further, the stress during summer season due to hot and humid weather may act as a predisposing factor (Khan et al., 2018) in Nadia outbreak.

After confirmation of the disease as DVE, attempt of primary isolation of virus was made in embryonated duck eggs for identification and experimental study. Isolation of virus was made successfully from infected liver, collected from outbreaks. Gross lesions on CAM and on embryos of infected embryonated eggs were similarly described earlier by Kulkarni et al., (1995). Death of embryo was usually found at 6- 8 days (Kulkarni et al., 1995) but in BudBud outbreak, embryonic death was noticed at 10 d.p.i. Death of embryonated duck eggs at 10 d.p.i. were also noticed in low virulent DEV isolates (Shawky et al., 2000).

The difference might be due to variation in virulence of virus causing field outbreaks. Identification of virus was carried out by characteristic embryopathy effects such as congestion and thickening of CAM, stunted embryo and haemorrhages on embryo. The virus was confirmed as DEV by a diagnostic PCR assay (amplicon size 610 bp).

In the present study, the pathogenicity of two DEV isolates was studied in khaki Campbell ducklings to characterize the nature of the isolates. Most of clinical signs observed in 28-day-old ducklings of the DEV infected groups (Gr I and Gr II) corroborate to the findings of earlier in khaki Campbell ducklings (Ray et al., 1983; Akter et al., 2004) and in Muscovy ducklings (Samadony et al., 2013). But there are certain differences found with respect to onset of clinical signs, duration of illness and character of diarrhoea between two infected groups which primarily attributed to the virulence.

In this study, gross pathological lesions in both infected groups are characteristics of DVE. Enlargement of spleen in infected groups substantiates the earlier finding of Shawky (2000) in induced white Pekin of two-week-old, indicating that the spleen is also a target organ of DEV.

The distinct variation of gross pathological lesions in esophagus, proventriculus, bursa and thymus among infected groups were noticed where virulence of the virus isolate would probably be an important factor. In present study, the severe haemorrhages on 
esophageal mucosa was found in khaki Campbell ducklings and similar observation was noticed in pathogenicity study with field isolate in Cherry Valley ducks of China (Li., et al., 2016). Whereas in Gr I, ulceration and formation of diphtheritic lesions in esophageal mucosal lining were observed which might be due to prolong course of disease as compared to Gr II infected group. Microscopic observations for all the tissues were characteristics of DVE and almost similar to the findings of Ray et al., (1983) and Kulkarni et al., (1995).

The difference in the tissue reaction and severity of lesions in Gr II may be due to more virulence compare to other isolate. Earlier study depicts severe haemorrhages with necrotic foci in parenchymatous organs, fatty degeneration in liver, lymphoid depletion with severe hyperaemia and haemorrhages in bursa during pathogenesis study in 20 days old white Pekin ducklings with high virulent isolate in China (Xuefeng et al., 2008).

The findings indicate that the one field isolate (DEV/Nadia/12) produces acute infection in ducklings and causes death of all birds in $\mathrm{Gr}$ II. It may be due to high virulence of the isolate. Another virus isolate (DEV/BudBud/11) showed delayed embryopathy, longer clinical course and recovery in induced duckling which indicate that the isolate may be of low virulent as compare to DEV/Nadia/12. Further detailed pathogenicity with large number of ducklings may be carried out for better understanding the nature of isolate in order to screen the challenged and vaccine candidates.

The present investigation diagnosed the outbreaks as duck virus enteritis caused by the duck enteritis virus. Furthermore, two isolates of different nature may be explored in preparation of attenuated vaccine.

\section{Acknowledgments}

The authors are grateful to Dean of the faculty and Principal Investigator of Rashtriya Krishi Vikash Yojana for providing excellent laboratory facilities to conduct research activities.

\section{References}

Akter, S., Islam, M. A., Hossain, M. T., Begum, M.I. A., Amin, M. M. and Sadekuzzaman, M. 2004. Characterization and pathogenicity of duck plague virus isolated from natural outbreaks in ducks of Bangladesh. Bangl. J. Vet. Med. 2:107-111.

Bancroft, J.D. and Stevens, A. 1996. Theory and practice of histological techniques. $4^{\text {th }}$ edition, London: Churchill Livingstone. p123.

Bhowmik, M. K. and Chakraborty, A. K. 1985.Occurrence of duck plague in ducklings of West Bengal. Indian J. Poult. Sci. 20:115-118.

Burgess, E. C. and Yuill, T. M. 1983.The influence of seven environmental and physiological factors on duck plague virus shedding by carrier mallards. J. of Wildlife Diseases. 19: 77-81.

Khan, K. A., Saha, S., Hossain, M. T., Haque, E., Haq, M. M. and Islam, M. A. 2018. Epidemiological investigation of recurrent outbreaks of duck plague in selected Haor (wetland) areas of Bangladesh. Journal of Advanced Veterinary and Animal Research. 5: 131-139.

King, A., Lefkowita, E. and Adams, M. J. 2011. Virus taxonomy: ninth report of the International Committee on Taxonomy of Viruses. Elsevier.

Konch, C, Upadhyaya, T.N., Goswami, S., and Dutta, B. 2009. Studies on the incidence and pathology of naturally occurring duck plague in Assam. Indian J. Vet.Pathol. 33:213-215.

Kulkarni, D. D., James, P. C. and Sulochana, S. 1995. Isolation of duck plague virus from ducks in Kerala state. Indian Vet. J. 72:446450.

Li, N., Hong, T., Li, R., Guo, M., Wang, Y., 
Zhang, J., Liu, J., Cai,Y., Liu, S., Chai, T., and Wei, L. 2016. Pathogenicity of duck plague and innate immune responses of the Cherry Valley ducks to duck plague virus. Scientific reports. 6:32183-8.

Mandal, P. S., Mukhopadhayay, S. K., Pradhan, S., Mondal, S., Jana, C., Patra, N. C. and Hansda, R. N. 2017. Development of nested polymerase chain reaction-based diagnosis of duck enteritis virus and detection of DNA polymerase gene from nondescriptive duck breed of West Bengal, India. Veterinary World, 10: 336-341.

Marius-Jestin, V., Cherbonnel, M., Picault, J. P. and Bennejean, G. 1987. Isolation from ducks of a hypervirulent strain of duck plague virus and an avian type 6 paramyxovirus. Comp Immunol Microbiol Infect Dis. 10:173-186.

Mondal, B., Rasool, T. J., Ram, H. and Mallanna, S. 2010. Propagation of vaccine strain of duck enteritis virus in a cell line of duck origin as an alternative production system to propagation in embryonated egg. Biologicals. 38:401-406.

Mukherji, A., Das, M. S., Ghosh, B.B. and Ganguly, J. L. 1963. Duck plague in West Bengal. Part I. Indian Vet. J.40:457-462.

Pazhanivel, N., Rajeswar, J., Ramprabhu, R., Manoharan, S., Bala, M. A., Balachandran, C., Kumanan, K., Prathaban, S. and Saahithya, R. 2019. Duck plague outbreak in a Chara-Chemballi duck farm. Iranian Journal of Veterinary Research. 20: 308312.

Ray, K., Chakraborty, A. K. and Bhowmik, M.K. 1983.Haematological, pathological and certain biochemical changes in experimentally infected indigenous duckling with duck- plague virus. Indian J. Anim. Sci. 53:45-49.

Reed, L. I. and Muench, H. 1938. A simple method for estimating 50 per cent end point. Am. J. Hyg.27: 493-497.

Salguero, F.J., Sanchez-Cordon, P.J., Nunez, A. and Gomez-Villamandos, J.C. 2002. Histopathological and ultra-structural changes associated with herpesvirus infection in waterfowl. Avian Pathology. 31:133-140.

Shawky, S. 2000.Target cells for duck enteritis virus in lymphoid organs. Avian Pathol.29:609-616. Shawky, S., Sandhu, T. and Shivaprasad, H. L.2000.Pathogenicity of a low-virulence duck virus enteritis isolate with apparent immunosuppressive ability. Avian Dis.44: 590-599. Umamaheswararao, S. and Rao, B.V. 1993. Assay of cell mediated immune responses of duck vaccinated against duck plague. Indian. J. Poult. Sci. 28: 256-258.

Soman M., Nair, S.R. and Mini. M. 2014. PCR Based Identification of Duck Virus Enteritis in Water Fowls in Kerala. Indian Journal of Natural Sciences. 5: 2148-2151.

Spieker, J. O., Yuill, T. M. and Burgress, E. C. 1996. Virulence of six strains of duck plague virus in eight waterfowl species. J. of Wildlife Diseases. 32: 453-460

Xuefeng, Q., Xiaoyan, Y., Anchun, C., Mingshu, W., Dekang, Z., Renyong, J. 2008. The pathogenesis of duck virus enteritis in experimentally infected ducks: a quantitative time- course study using TaqMan polymerase chain reaction. Avian Pathol. 37:307-310.

\section{How to cite this article:}

Jana, C., S. K. Mukhopadhayay, S. N. Joardar and Mondal, B. 2021. Preliminary Investigation of Outbreaks of Duck Virus Enteritis in Khaki Campbell Ducks in West Bengal. Int.J.Curr.Microbiol.App.Sci. 10(01): 3187-3197. doi: https://doi.org/10.20546/ijcmas.2021.1001.371 